Supporting Information:

\title{
High-Temperature Proton Conduction in Covalent Organic Framework Interconnected with Nanochannel for Reverse Electrodialysis
}

Rahul Singh ${ }^{a}$, and Daejoong Kima*

aDepartment of Mechanical Engineering, Energy-Water Nexus Lab, Sogang University, 35Baekbeom-Ro, Mapo-Gu, Seoul,121-742, Republic of Korea

*Corresponding Author

Authors email address:

singhrs@sogang.ac.kr (RS)

daejoong@sogang.ac.kr (DK)

Number of pages: 37

Number of figures: 22

Number of tables: 03

Number of notes: 03 


\section{Content:}

1. Methods and Techniques

2. Note S1: Nanostructure estimation using SAXS analysis

3. Table S1: Small Angle X-ray scattering of Nafion and sPEEK based ionomer

4. Figure S1: Photograph of hydrated and dry membrane

5. Figure S2: Wide-angle X-ray diffraction pattern of FAA-3 and Nafion membrane

6. Figure S3: X-ray diffraction of COF and MIM

7. Figure S4: FT-IR of prepared membranes

8. Figure S5: HR-TEM image of the membrane

9. Figure S6: HR-TEM image of COF particle

10. Figure S7: Free-standing membranes and their solution concentration photograph

11. Figure S8: Thermogravimetric analysis of the covalent organic framework

12. Figure S9: Thermogravimetric Analysis of linker for covalent organic framework

13. Figure S10: Differential scanning calorimetry

14. Figure S11: Tensile test of the pristine membrane in a dry state

15. Figure S12: Photograph of the water droplet on the hydrophilic surface

16. Figure S13: Time-dependent contact angle measurement

17. Figure S14: AFM micrograph of the membrane

18. Figure S15: FE-SEM image of membrane morphology and thickness

19. Figure S16: Energy-dispersive X-ray spectroscopy mapping

20. Table S2: Table of energy-dispersive X-ray spectroscopy mapping.

21. Table S3: List of COF material and their proton conductivity comparison

22. Note S2: Theoretical and Experimental parameter of RED

23. Figure S17: RED output performance using COF based MIM

24. Figure S18: Photograph of the large area membrane and stack

25. Note S3: Internal resistance of the stack

26. Figure S19: Internal resistance and long-run stability of the RED stack

27. Figure S20: Digital photograph of synthesized materials

28. Figure S21: Nuclear magnetic resonance (NMR) spectra (500 MHz, DMSO-d6)

29. Figure S22: Surface area and Pore size distribution of the prepared COF

30. Nomenclature

31. References 


\section{Methods and Techniques}

Small Angle X-ray Scattering (SAXS) measurement was performed at the $4 \mathrm{C}$ beamline of the Pohang Accelerator Laboratory (PAL) in Korea. The distance between the sample and the charge-coupled device (CCD) was kept fixed, and the wavelength $(\lambda)$ of the X-ray beam was $0.73 \AA$. The exposure time was about 100 seconds per sample, and the d-spacing was calculated using Bragg`s distance. XRD [Rigaku (MiniFlex, Japan)] operated at $30 \mathrm{kV}$ and $15 \mathrm{~mA}$ with graphite-monochromatized $\mathrm{CuK} \alpha$ radiation $(\lambda=1.542 \AA)$. XRD measurements were performed over the $2 \theta$ range from $5^{\circ}$ to $50^{\circ}$ for PEEK, sPEEK samples and $3^{\circ}$ to $50^{\circ}$ for COF based MIM sample with a step size of $0.02{ }^{\circ}$ under scanning rate $2{ }^{\circ}$ per min. $\mathrm{N}_{2}$ adsorption-desorption isotherms measurement used for determining the surface area and pore size distribution and were carried out using Micromeritics Instrument (TriStar II 3020). FT-IR spectroscopy (Thermo-Nicolet AVATAR 380 FT-IR Spectrometer, USA) measurement performed at absorption mode under spectral range 650 to $4000 \mathrm{~cm}^{-1}$. The Attenuated Total Reflectance (ATR) method used for obtaining a quantitative analysis of the membrane. The main peak of both membranes were lies near the lower wavenumber from 650-1500 $\mathrm{cm}^{-1}$. HR-TEM (JEM 2100F) with an accelerating voltage $\mathrm{A} 1=3.24$ and $\mathrm{A} 2=$ 7.39 $\mathrm{kV}$ used for material analysis. Few particles of COF and solution of the hybrid membrane spread over 300 mesh copper TEM grids. FE-SEM [JSM-7100F (JEOL, Japan)] used to study the surface morphology of the membranes. All samples were transferred to liquid nitrogen for 2-3 min before cutting for the membrane cross-section image. Before the measurements, the surfaces of all samples were uniformly sputter-coated 3-5nm with platinum. Whereas Park system NX10 (Republic of Korea), based AFM used to record the 3D topography of the prepared membrane; by using a non-contact cantilever (NSC15 10M). The noise-free surface scanning was performed by fixing the distance between the 
tip and the sample on tens to hundreds of angstroms. Time-dependent contact angle measurement was performed by Femtobiomed (smartdrop, Republic of Korea). Generally, 300-600 points were acquired from the free surface droplet, the camera equipped with a frame rate of up to $50 \mathrm{fps}$. All samples were analyzed using smartdrop software by the Bashforth-Adam equation. The thermal measurement of the prepared material and membrane was performed by Differential Scanning Calorimeters (DSC) TA instrument (TA Q20, USA). All membranes were measured in-between temperature range 50 to $250{ }^{\circ} \mathrm{C}$ under a nitrogen flow rate of $50 \mathrm{~mL} \mathrm{~min}^{-1}$. Thermogravimetric analysis (TA Q50, USA) measures the thermal performance of the membrane in the temperature range of 50 to $700{ }^{\circ} \mathrm{C}$. The initial mass of the sample recorded by weighing-balance and placed in the platinum pan. Mass loss is recorded at a sampling rate of $10{ }^{\circ} \mathrm{C} \mathrm{min}^{-1}$ under $\mathrm{N}_{2}$ atmosphere; the flow rate maintained at $40 \mathrm{~mL} \mathrm{~min}^{-1}$ for each sample. Universal Testing Machine (UTM) [SHIMADZU, AG-X plus 500N] measurement carried out to investigate the tensile properties of prepared membranes. A crosshead speed of 0.5 $\mathrm{mm} \cdot \mathrm{min}^{-1}$ maintained for all the samples. The tensile test performed according to ASTM d882-10. Electrochemical impedance spectroscopy (EIS) measurement was carried out by a Biologic instrument. The bulk resistance determined the conductivity of the prepared hybrid membranes using the equation: $\sigma=\mathrm{L} /\left(\mathrm{R}_{\mathrm{b}} \cdot \mathrm{W} \cdot \mathrm{T}\right)$. Where, $\mathrm{R}_{b}$ is the bulk resistance of membrane, $\mathrm{W}$ is the width, $\mathrm{T}$ is the thickness of the sample, and $\mathrm{L}$ is the distance between electrodes. The membrane water uptake measured by determining weights before and after soaking at a varying temperature from 25 to $120^{\circ} \mathrm{C}$ for $6 \mathrm{~h}$. The water uptake was determined using the $\mathrm{WU}(\%)=100 \cdot\left(\mathrm{W}_{\text {wet }}-\mathrm{W}_{\text {dry }}\right) / \mathrm{W}_{\text {dry. }}$. The membrane water swelling was measured using following equation $W_{S t}(\%)=100 \cdot\left(t_{\text {wet }}(\mu \mathrm{m})-t_{d r y}\right.$ $(\mu \mathrm{m})) / \mathrm{t}_{\mathrm{dry}}(\mu \mathrm{m})$ and $\mathrm{W}_{\mathrm{Sl}}(\%)=100 \cdot\left(\mathrm{l}_{\mathrm{wet}}(\mathrm{mm})-\mathrm{l}_{\mathrm{dry}}(\mathrm{mm})\right) / \mathrm{l}_{\mathrm{dry}}(\mathrm{mm})$. 


\section{Notes S1 Nanostructure estimation using SAXS analysis:}

Nanolevel phase separation takes place due to the presence of hydrophobic and hydrophilic groups in the membrane. This phase-separation in the membrane gives rise to a broad ionomer peak in the small-angle X-ray scattering graph. Typically, two maxima were observed from the SAXS graph; the first one at the lower q side represents the crystalline domain. The second one at a relatively higher q side represents the ionic nanochannel of sPEEK polymer ${ }^{1}$. The width of the phase-separated polymer nanochannel is directly determined from the Bragg spacing $(\mathrm{d})^{2}$.

$$
\mathrm{d}(\AA)=\frac{2 \pi}{q\left(\AA^{-1}\right)}
$$

In the case of only one peak appears in the SAXS graphs of the membrane, it signifies that the ionic species concentration is very high > 50\%; therefore, the crystalline domain peak is absent in graph ${ }^{3}$. When the dry membrane transforms into the hydrated membrane, the peak shift observed in both the ionomer peak and inter-crystalline peak position towards the lower q side 4 .

All $\mathrm{R}_{\mathrm{g}}$ values are estimated from the Guinier approximation by using equation $(2)^{5}$ :

$$
I(q)=I(0) \exp \left[-\frac{q^{2} R_{g}^{2}}{3}\right]
$$

Where $\mathrm{I}(\mathrm{q})$ is the scattering intensity, $\mathrm{I}(0)$ is the forward X-ray scattering intensity, $\mathrm{R}_{\mathrm{g}}$ is the radius of gyration, and the scattering vector is q evaluated from $\left(\frac{4 \pi}{\lambda}\right) \sin \theta, \lambda$ is the wavelength of incident X-ray, $\theta$ is half the scattering angle. All membranes show $\mathrm{R}_{\mathrm{g}}$ values above $1.3 \AA$, which is a good indication of a well-distributed nano-chain of nanochannel networks throughout the membrane. 
Table S1 Width of polymer nanochannel and its corresponding q value for both dry and hydrated membranes.

\begin{tabular}{|l|l|l|}
\hline Ionomer & sPEEK (1.8 meq/g) & Nafion \\
\hline Dry membrane $\left(25^{\circ} \mathrm{C}\right)$ & $\sim 0.19$ & $\sim 0.18$ \\
\hline q value & $\sim 3.2$ & $\sim 3.5$ \\
\hline d-spacing (nm) & \multicolumn{2}{|l|}{} \\
\hline Hydrated membrane $\left(80^{\circ} \mathrm{C}\right)$ & $\sim 0.1$ \\
\hline q value & $\sim 0.138$ & $\sim 5.8$ \\
\hline d-spacing (nm) & $\sim 4.5$ & \\
\hline
\end{tabular}




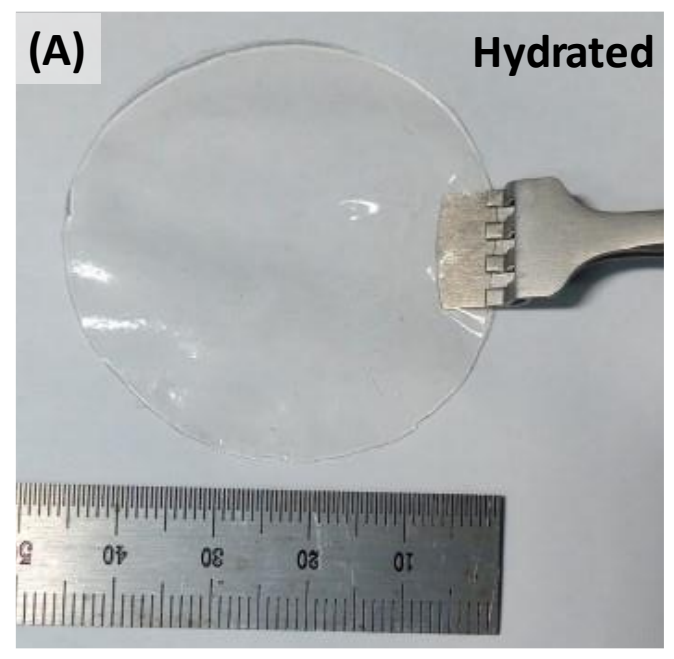

(C)

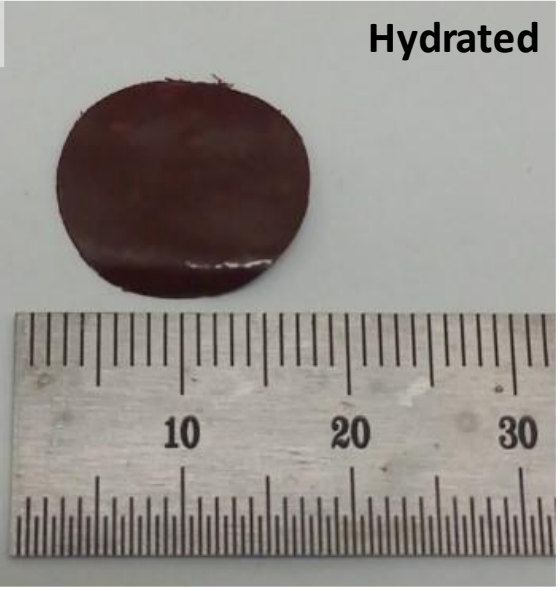

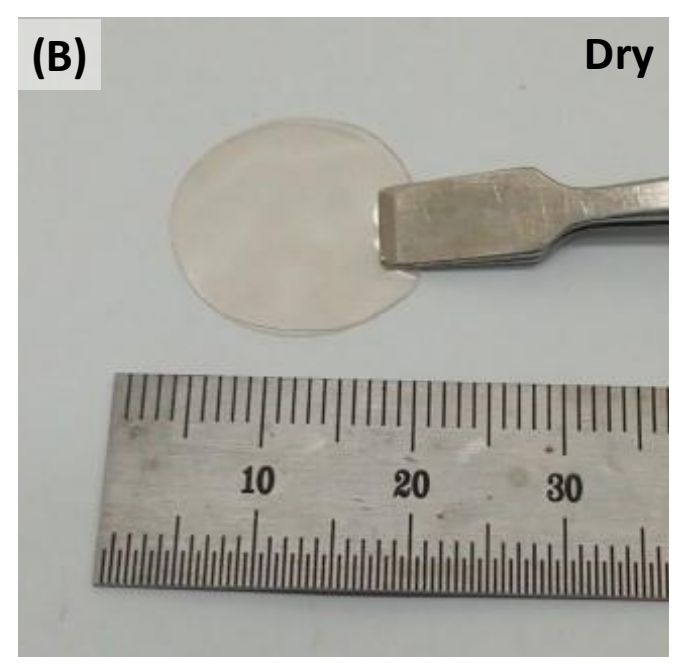

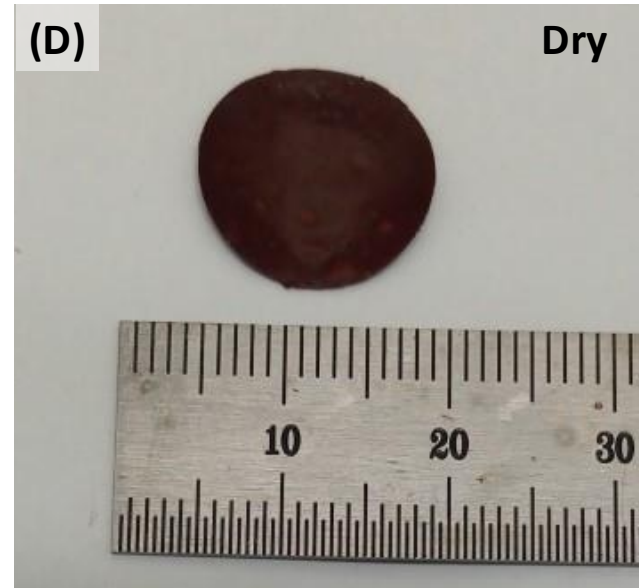

Figure S1 Photograph of hydrated and dry membrane: (A) Hydrated image of sPEEK membrane at $80^{\circ} \mathrm{C}$, (B) Dry membrane of sPEEK polymer, (C) COF matrix interconnected membrane under-hydrated state at $80^{\circ} \mathrm{C}$, and (D) COF matrix interconnected membrane under dry state. 
(A)

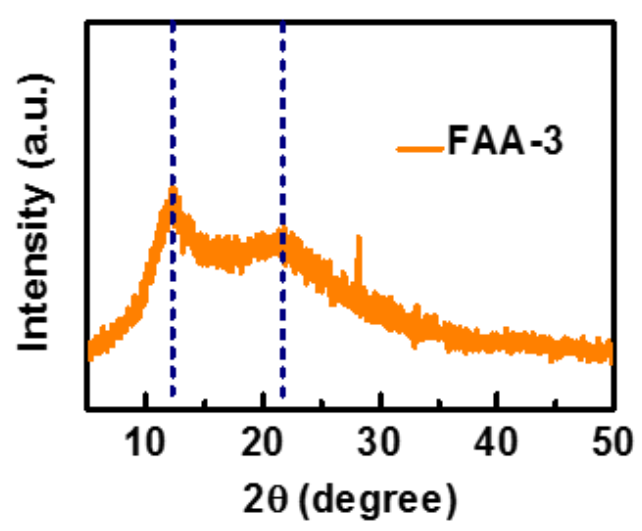

(B)

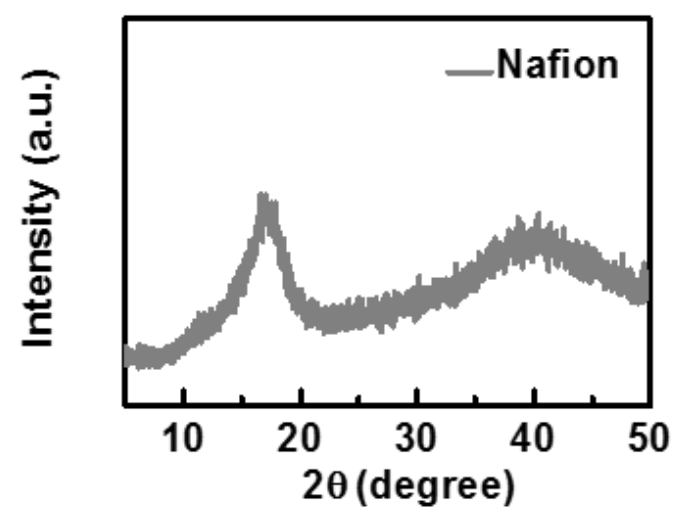

Figure S2 X-ray diffraction pattern: (A) FAA-3 membrane, and (B) Nafion membrane 
(A)

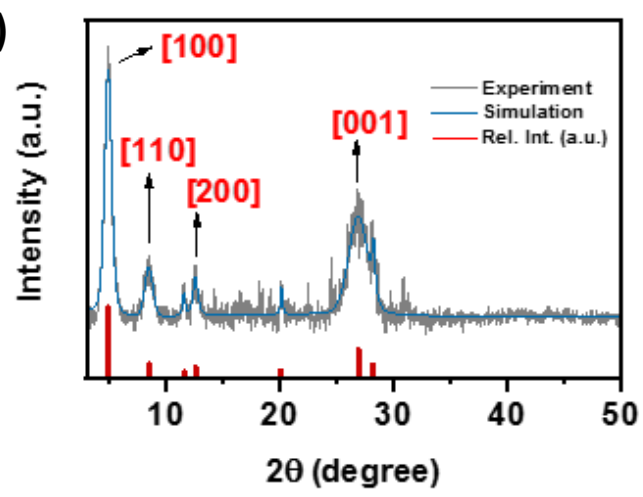

(B)

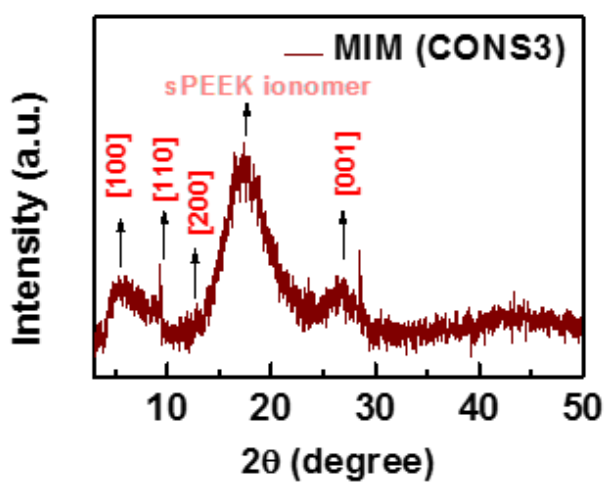

Figure S3 X-ray diffraction of COF and MIM: (A) Covalent organic framework in powder form, and (B) COF based matrix interconnected membrane using sPEEK (MIM). 
(A)

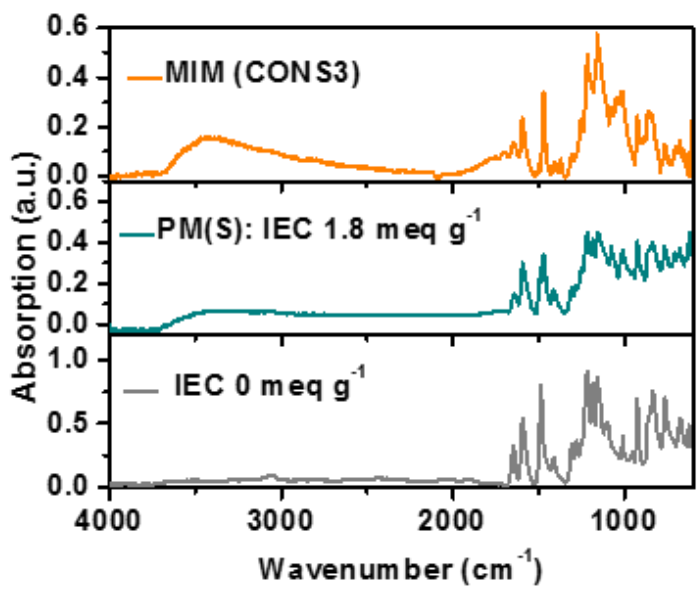

(B)

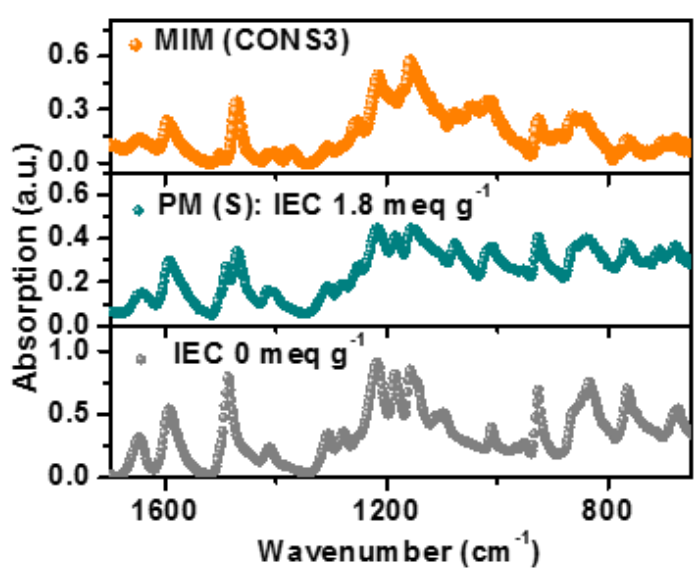

Figure S4 FT-IR spectroscopy: (A) Full spectra of COF matrix interconnected membrane, sulfonated-PEEK membrane, PEEK polymer, and (B) spectral region 1700 to $650 \mathrm{~cm}^{-1}$. 

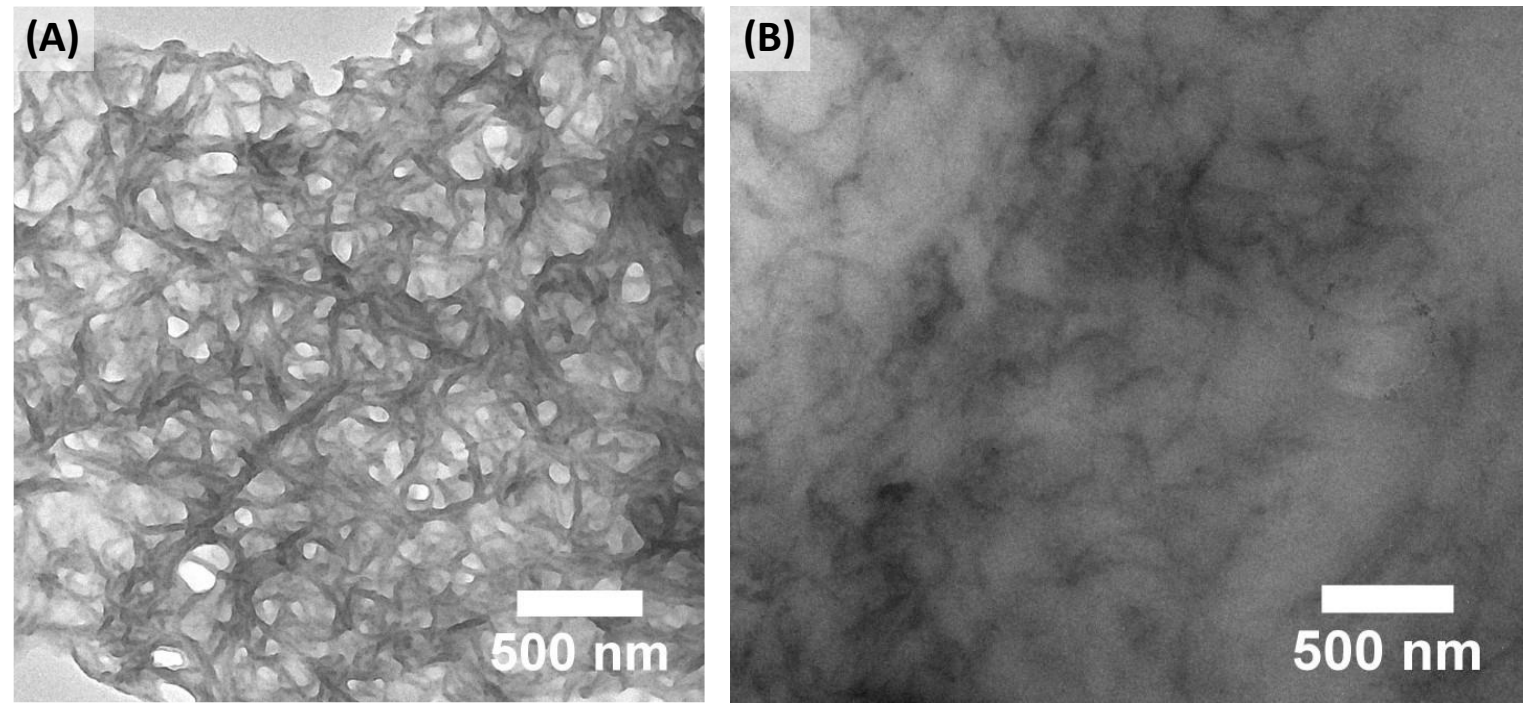

Figure S5 HR-TEM image of prepared membrane: (A) well-distributed crystallineorganic network with sulfonated-PEEK polymer, and (B) Surface morphology of low concentration of crystalline-organic framework in sPEEK polymer matrix. 

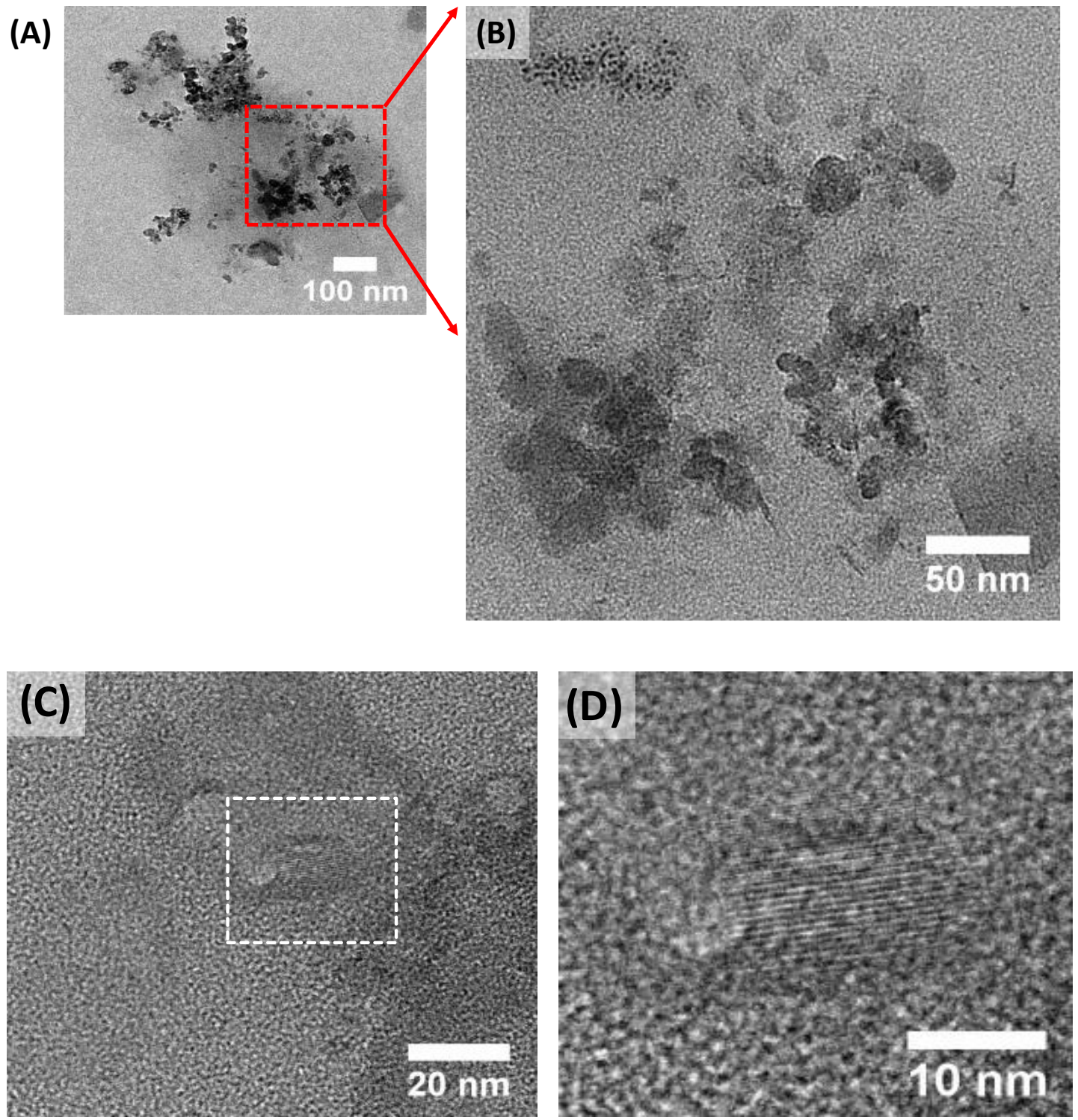

Figure S6 HR-TEM of COF powder: (A) HR-TEM micrograph of covalent organic framework particle with scale $100 \mathrm{~nm}$, (B) scale $50 \mathrm{~nm},(C)$ scale $20 \mathrm{~nm}$, and (D) scale10 nm. 


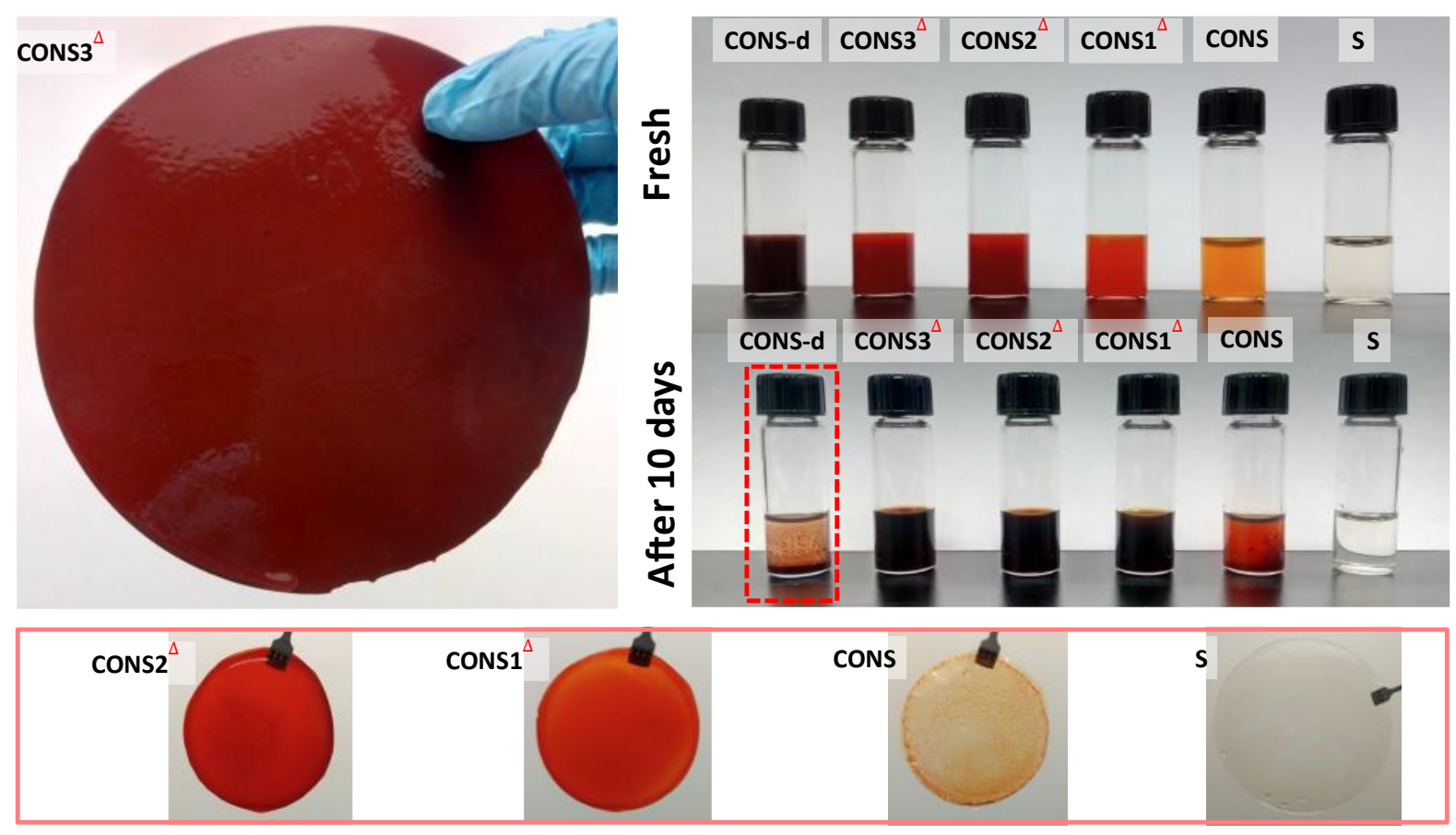

Figure S7 Free-standing membranes and its solution: " $S$ " is the sPEEK solution in DMAc solvent, CONS is the mixture of 1,3,5-tri formyl phloroglucinol, pPhenylenediamine, $\mathrm{p}$-Toluenesulfonic acid in sPEEK solution without heating, CONS1 $\Delta$ is 0.05 wt. $\%$ of COF precursor material after heating, CONS2 $\Delta$ is $0.1 \mathrm{wt} . \%$ of COF precursor material after heating, CONS3 $\Delta$ is $0.5 \mathrm{wt} . \%$ of COF precursor material after heating, and CONS-d represents the sample made from sPEEK ionomer solution mixed directly with COF powder. 


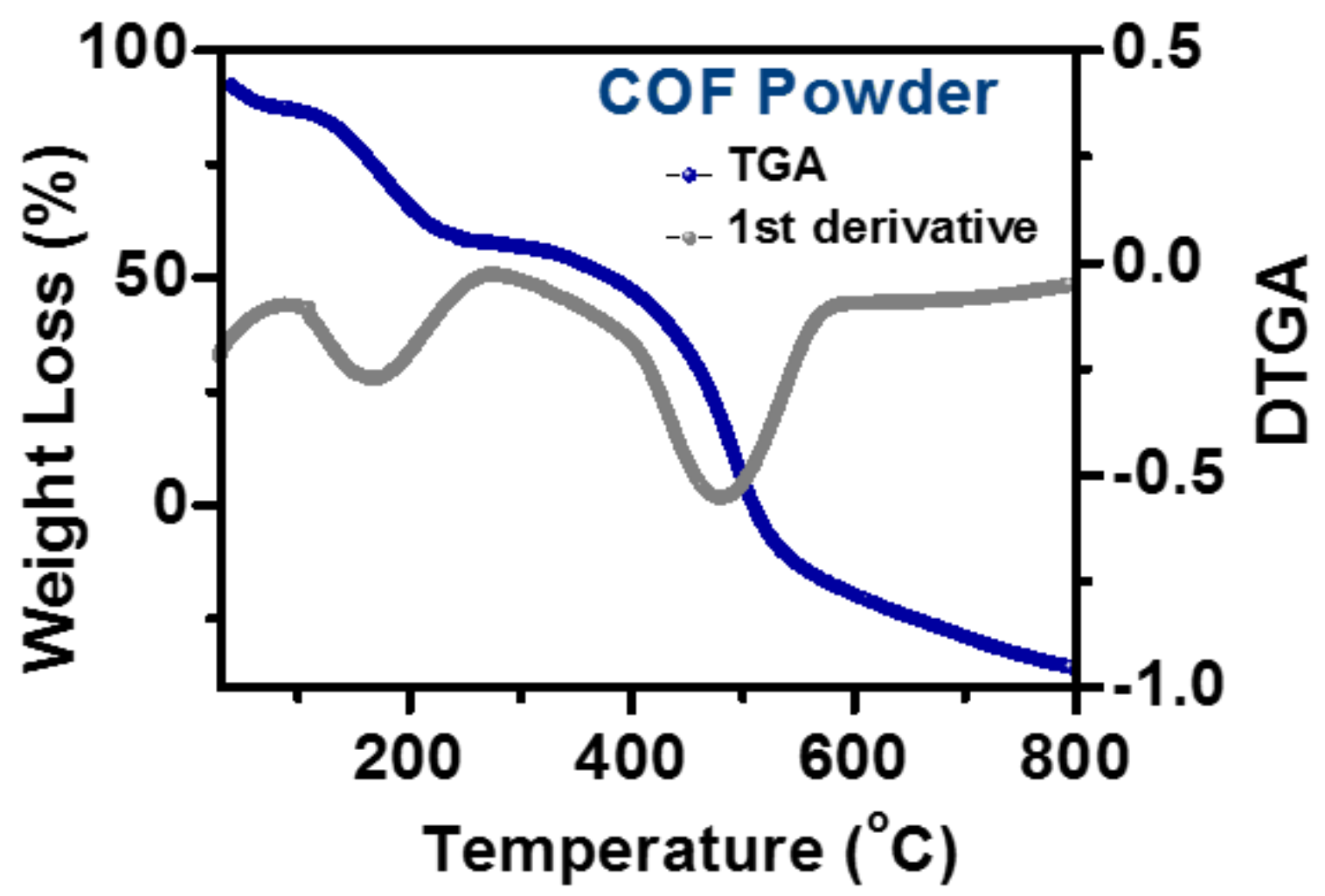

Figure S8 Thermogravimetric analysis of Covalent organic framework as-synthesized and its first derivative curve. 
(A)

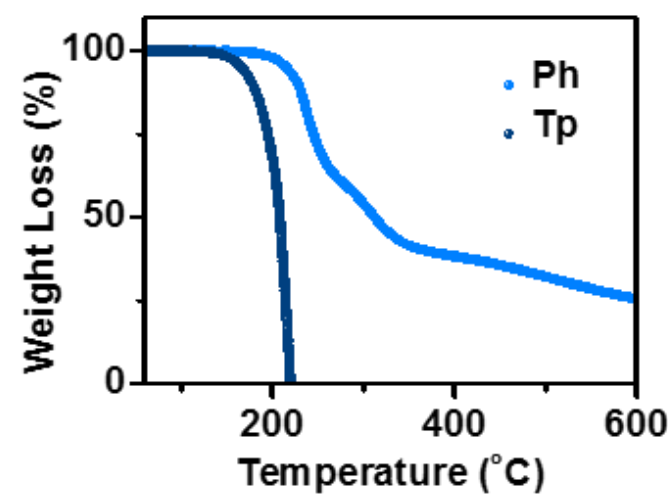

(B)

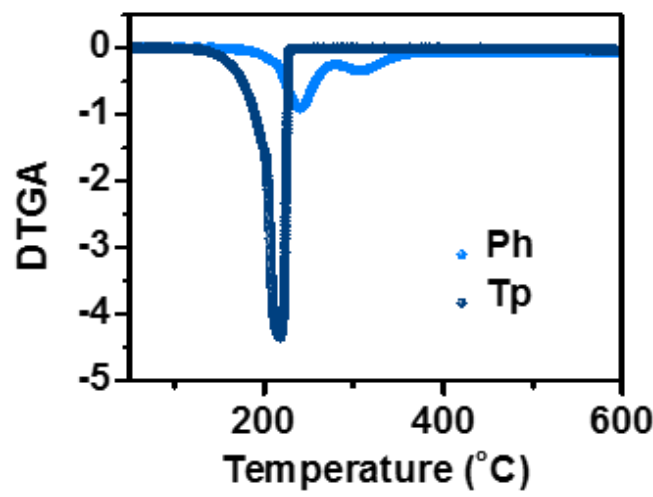

Figure S9 Thermal analysis of linker: (A) Thermogravimetric analysis of pure phloroglucinol and 1,3,5-tri formyl phloroglucinol, and (B) First derivative curve of pure phloroglucinol and 1,3,5-tri formyl phloroglucinol. 


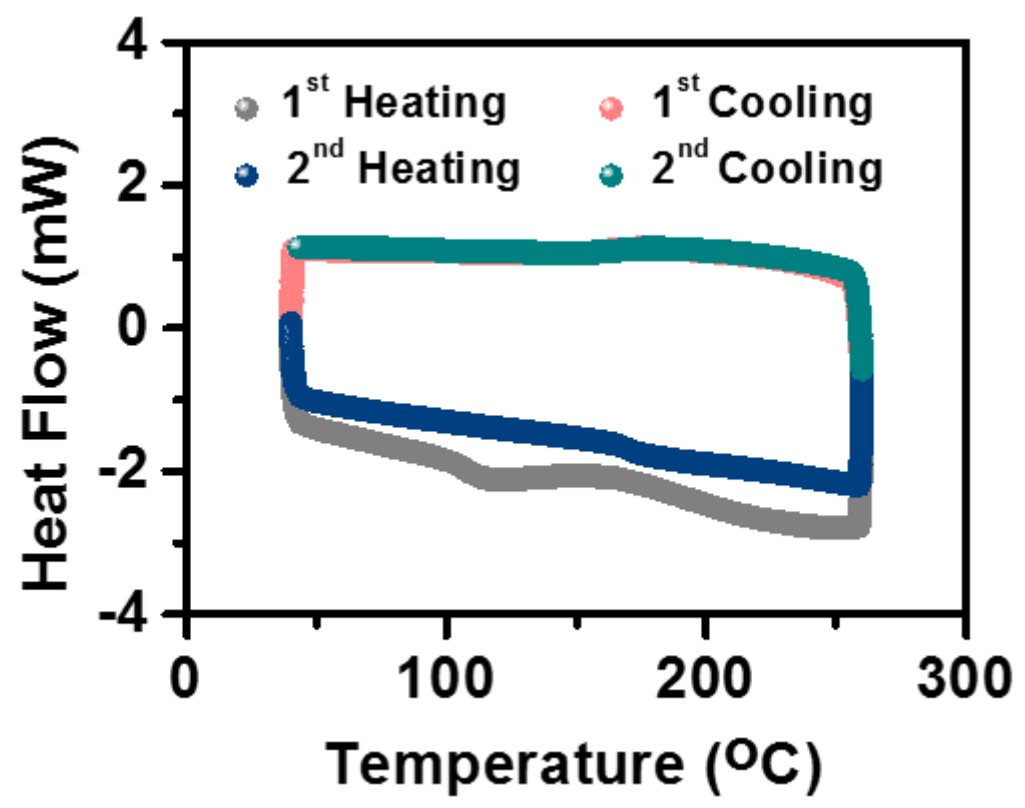

Figure S10 Differential scanning calorimetry (DSC): Scan of DSC thermograms represents a two-cycle that starts from $40^{\circ} \mathrm{C}$ till $260^{\circ} \mathrm{C}$, the temperature drops down till $40{ }^{\circ} \mathrm{C}$ completing the first cycle. In the second cycle, the temperature starts to rise from $40{ }^{\circ} \mathrm{C}$ reaching $260^{\circ} \mathrm{C}$, and then returns to the initial temperature. 


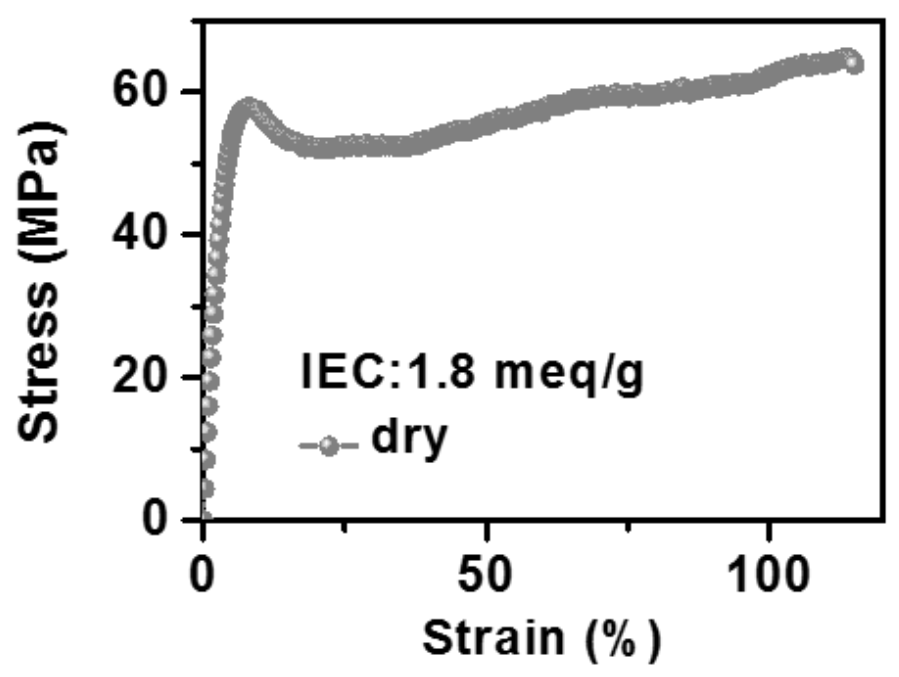

Figure S11 Tensile test: strain versus stress plot of the pristine sPEEK dry membrane. 

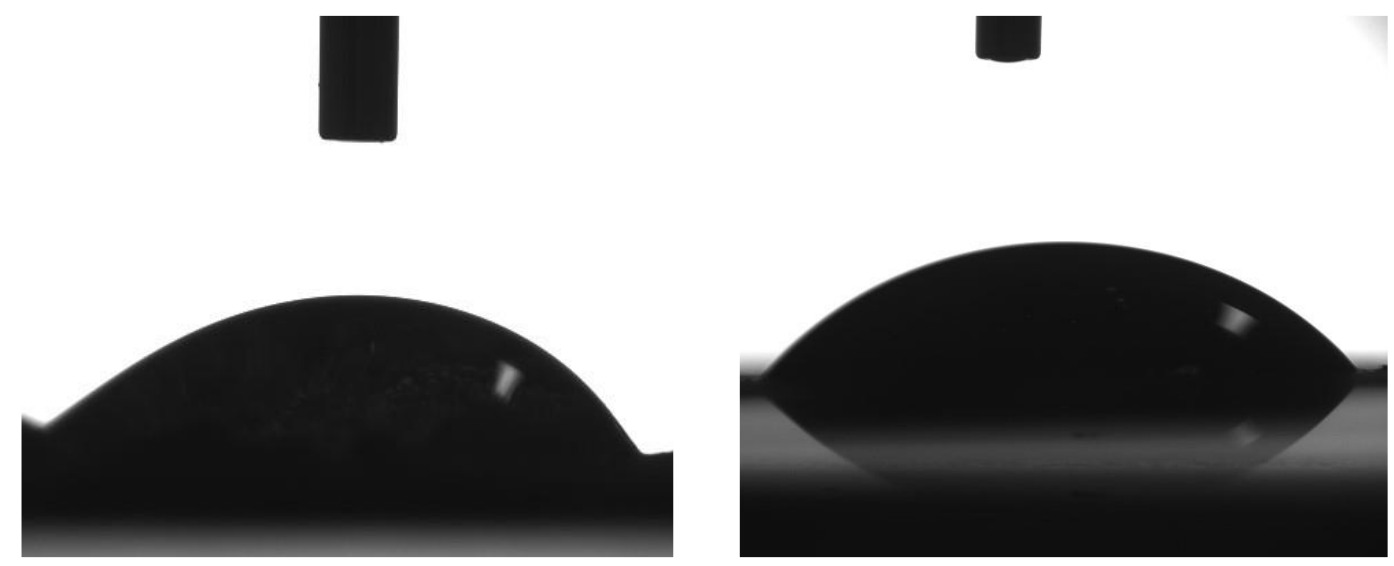

Figure S12 Photograph of water droplets on the hydrophilic surface of the membrane after treatment with chlorosulfonic acid. 
(A)

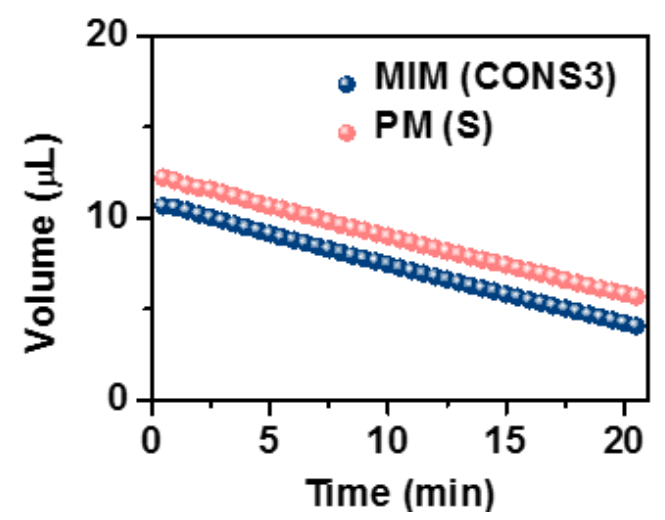

(B)

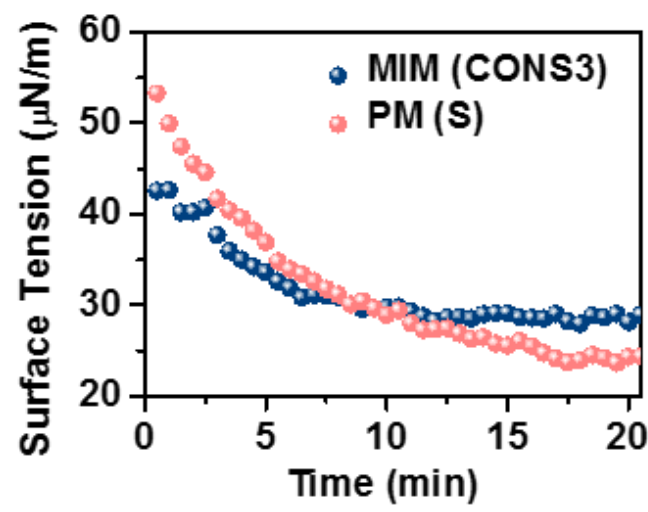

Figure S13 Time-dependent contact angle measurement: (A) Volume measurement of an initial and final water droplet on the membrane, and (B) Surface tension measurement of the initial and final water droplet on the sPEEK membrane and COF based matrix interconnected membrane. 

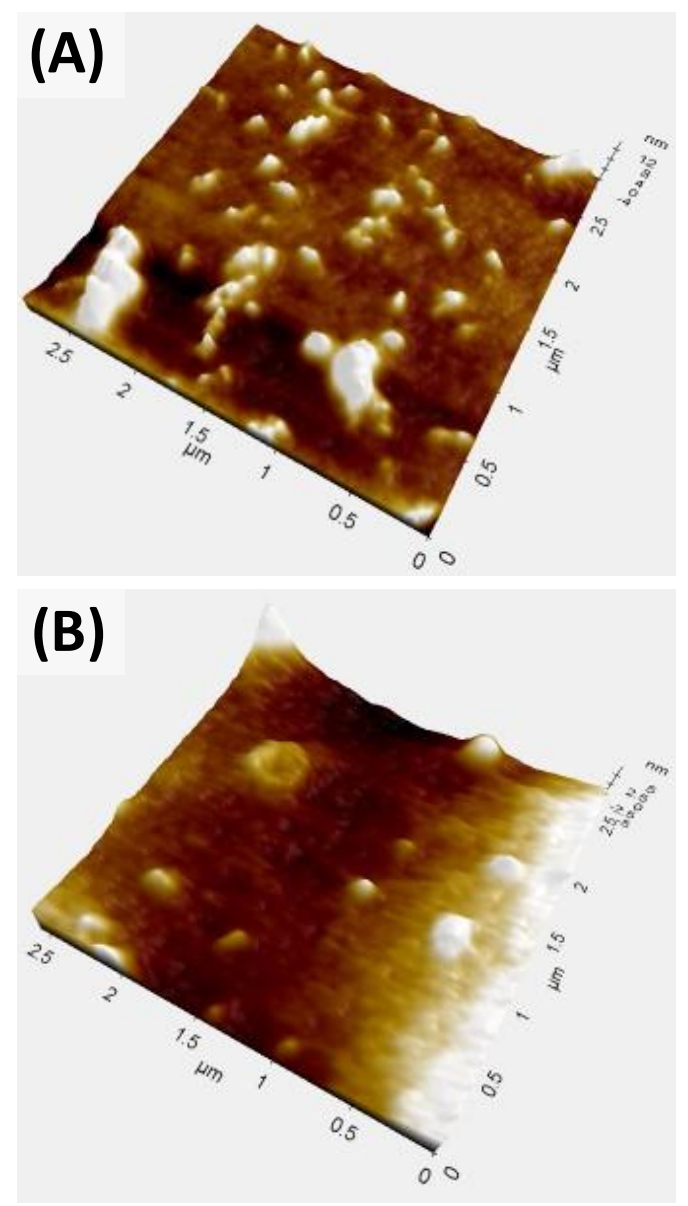

(C)

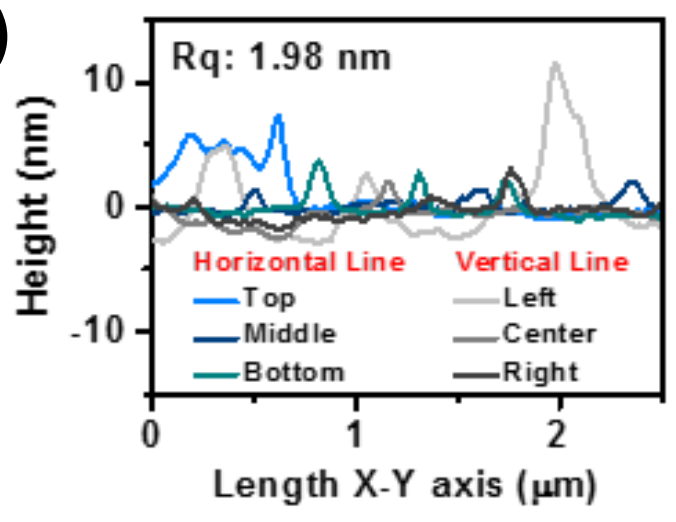

(D)

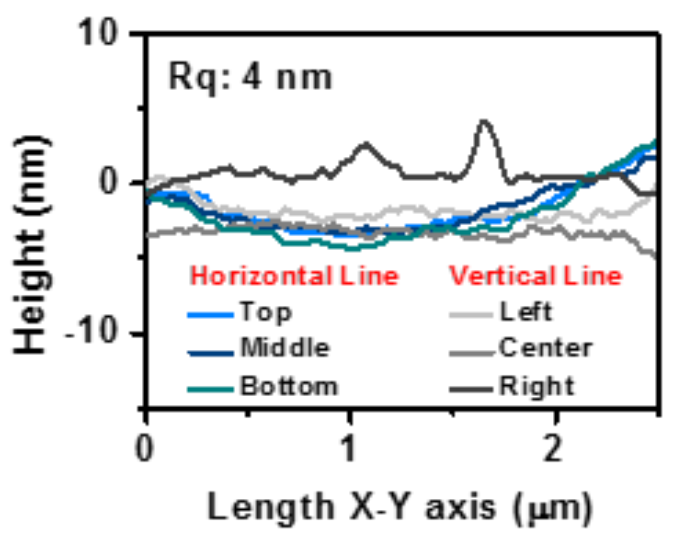

Figure S14 Atomic force morphology: (A) AFM micrograph of sulfonated-PEEK, (B) AFM micrograph of covalent-organic framework matrix interconnected membrane, (C) Surface roughness of the sPEEK membrane, and (D) Surface roughness of covalentorganic framework matrix interconnected membrane. 


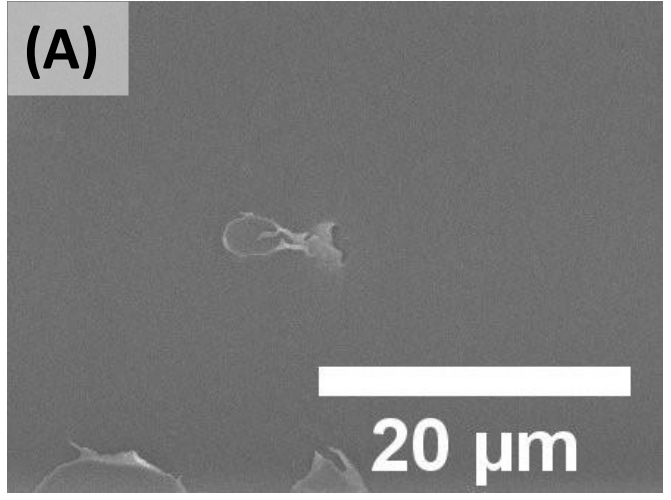

(C)

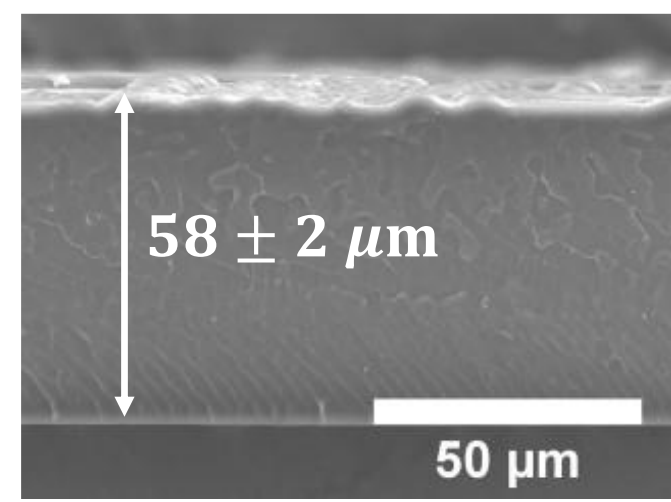

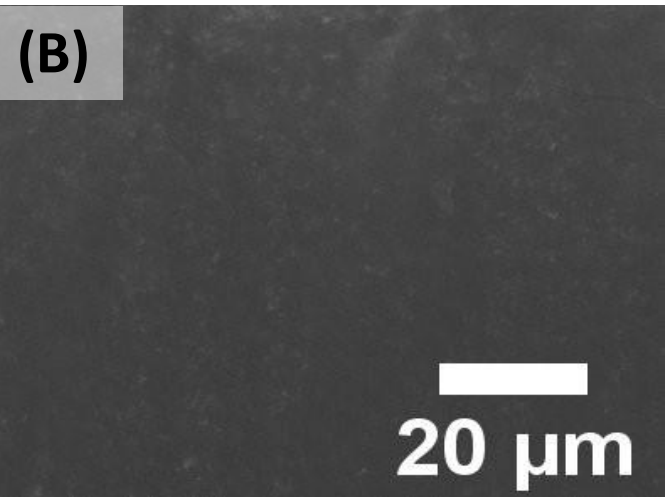

\section{(D)}

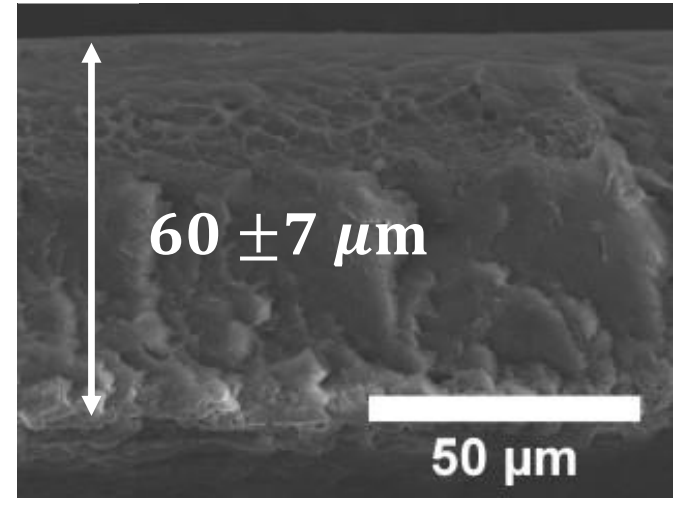

Figure S15 FE-SEM image of membrane morphology and thickness: (A) surface morphology of sPEEK membrane, (B) surface morphology of COF matrix interconnected membrane, (C) Cross-section micrograph of the sulfonated-PEEK membrane, and (D) Cross-section image of COF-based matrix interconnected membrane. 


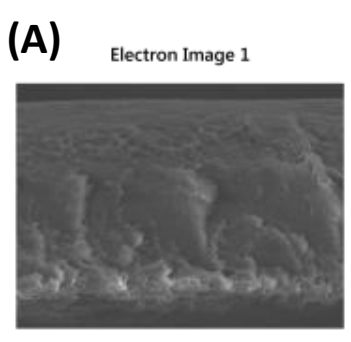
$\longdiv { 2 5 \mu m }$

(D)

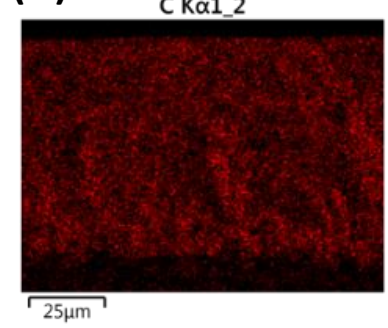

(B) EDS Layered Image 1

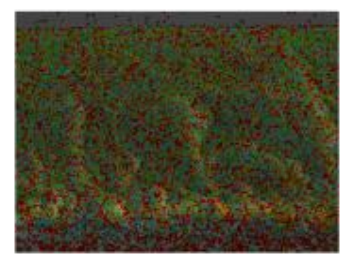

$\longdiv { 2 5 \mathrm { um } }$

(E)

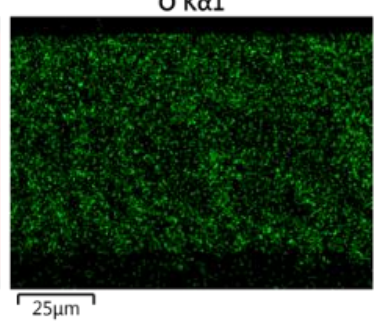

(C)

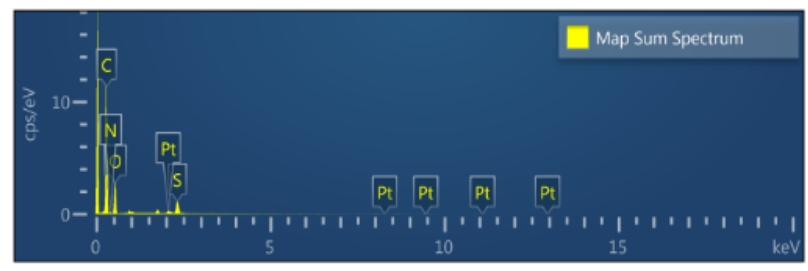

(F)

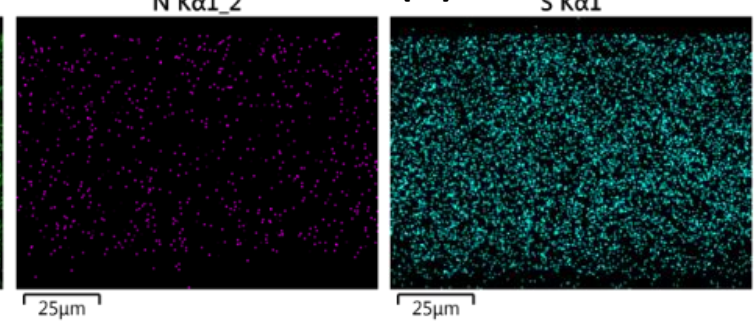

Figure S16 Energy-dispersive X-ray spectroscopy mapping: (A) Cross-section image of COF based membrane at scale $25 \mu \mathrm{m}$, (B) Cross-section image with energy-dispersive $\mathrm{X}$-ray spectroscopy mapping with different element, (C) plot of energy-dispersive X-ray spectroscopy mapping showing different element, (D) carbon mapping, (E) oxygen mapping, (F) nitrogen mapping, and (G) sulfur mapping. 
Table S2 Different elements and their concentration determined from energy-dispersive $\mathrm{X}$-ray spectroscopy mapping.

\begin{tabular}{|l|l|l|l|l|l|}
\hline Element & Line Type & $\begin{array}{l}\text { Apparent } \\
\text { Concentration }\end{array}$ & K Ratio & Atomic \% & Wt\% \\
\hline $\mathbf{C}$ & K series & 1.36 & 0.0135 & 73.5 & 67.28 \\
\hline $\mathbf{N}$ & K series & 0.09 & 0.00015 & 4.0 & 4.27 \\
\hline $\mathbf{O}$ & K series & 0.60 & 0.0020 & 21.56 & 26.27 \\
\hline $\mathbf{S}$ & K series & 0.14 & 0.0011 & 0.9 & 2.18 \\
\hline Total & & & & 100 & 100 \\
\hline
\end{tabular}


Table S3 List of COF material and their proton conductivity comparison.

\begin{tabular}{|c|c|c|}
\hline Sample & Ion Conductivity $\left(\mathrm{S} \mathrm{cm}^{-1}\right)$ & Reference \\
\hline MIM (COF-i- sPEEK: $\mathrm{SO}_{3} \mathrm{H}$ ) & 0.088 at $80{ }^{\circ} \mathrm{C} ; 100 \% \mathrm{RH}$ & This work \\
\hline SPEEK@OX-BD-COF-SO $3 \mathrm{H}$ & $6.22 \times 10^{-3}$ at $90^{\circ} \mathrm{C} ; 98 \% \mathrm{RH}$ & 6 \\
\hline SPEEK@OX-BD-COF-SO 3 H & $3.87 \times 10^{-3}$ at $90^{\circ} \mathrm{C} ; 98 \% \mathrm{RH}$ & 6 \\
\hline NUS-10(R)@PVDF-50 & $1.58 \times 10^{-2}$ at $80^{\circ} \mathrm{C} ; 97 \% \mathrm{RH}$ & 7 \\
\hline phytic@TpPa-(SO3 H-Py) & $5.00 \times 10^{-4}$ at $120^{\circ} \mathrm{C}$ & 8 \\
\hline PA@Tp-Azo & $9.90 \times 10^{-4}$ at $59^{\circ} \mathrm{C} ; 98 \% \mathrm{RH}$ & 9 \\
\hline PA@TpBpy-MC & $2.50 \times 10^{-3}$ at $120^{\circ} \mathrm{C}$ & 10 \\
\hline PTSA@TpAzo & $7.80 \times 10^{-2}$ at $80^{\circ} \mathrm{C} ; 95 \% \mathrm{RH}$ & 11 \\
\hline im@TPB-DMTP-COF & $4.37 \times 10^{-3}$ at $130^{\circ} \mathrm{C}$ & 12 \\
\hline EB-COF:PW 12 & $3.32 \times 10^{-3}$ at $25^{\circ} \mathrm{C} ; 97 \% \mathrm{RH}$ & 13 \\
\hline BIP & $3.20 \times 10^{-2}$ at $95^{\circ} \mathrm{C} ; 95 \% \mathrm{RH}$ & 14 \\
\hline 2D-aza-COF-1 & $1.51 \times 10^{-5}$ at $50^{\circ} \mathrm{C} ; 97 \% \mathrm{RH}$ & 15 \\
\hline RT-COF-1 & $1.83 \times 10^{-5}$ at $39{ }^{\circ} \mathrm{C} ; 100 \% \mathrm{RH}$ & 16 \\
\hline $\mathrm{H}_{3} \mathrm{PO}_{4} @ \mathrm{NKCOFs}$ & $1.13 \times 10^{-1}$ at $80^{\circ} \mathrm{C} ; 98 \% \mathrm{RH}$ & 17 \\
\hline
\end{tabular}




\section{Note S2 Theoretical and Experimental parameter}

Typically, the total power obtained from the RED stack is the power generated from equation (3) from ${ }^{18-19}$

$$
P_{\text {max }}=\frac{U_{\text {Stack }} \cdot I_{\text {Stack }}}{A_{\text {mem }}}
$$

Where $P_{\max }$ is the maximum power density of the stack $\left(\mathrm{W} \mathrm{m}^{-2}\right), \mathrm{U}_{\text {stack }}$ is the voltage $(\mathrm{V})$ generated by the membrane stack, Istack is the scanned current (A), and $A_{\text {mem }}$ is the effective area of the membrane $\left(\mathrm{m}^{2}\right)$. This output power of the RED stack requires subtracting by hydrodynamic power loss (pumping loss), which is given by the following equation (4).

$$
P_{\text {net }}=P_{\max }-P_{\text {loss }}
$$

Here, Ploss is pumping power loss generated in the RED compartment by internal loss and expressed as a function of the pressure drop $(\Delta P)$ over inlet and outlet of feed flow solution, flow rate $(\mathrm{Q})$, and pump efficiency $\left(\eta_{\text {pump }}\right)^{20-21 .}$

$$
P_{\text {loss }}=\frac{\Delta P_{H} Q_{H}+\Delta P_{L} Q_{L}}{\eta_{\text {pump }}}
$$

In RED, the pressure drop is estimated theoretically using the Darcy-Weisbach equation ${ }^{22}$ by supposing an ideal system with a laminar flow of liquid in an infinite wide uniform channel. However, the hydraulic diameter of the channel $d_{h}(\mathrm{~m})$ for infinite wide channel is equal to $2 \mathrm{~h}$.

$$
\Delta P=\frac{12 \mu \cdot L^{2}}{t_{\text {res }} \cdot \frac{1}{4} \cdot d_{h}^{2}}
$$

The gap between the hybrid membrane and FAA-3 based membranes denoted by ' $b$ ', and the value of hydraulic diameter expressed by equation 723 .

$$
d_{h}=\frac{4 b \cdot h}{2 b+2 h}
$$

The value of $d_{h}$ calculated from equation 7 for the infinite wide channel is much lower than the value obtained from the finite wide channel. The low value is due to the nonuniformity of inflow and outflow of feed waters whereas, the spacer filament restricts flowing water increasing by pumping power. Thus, knowing the ratio of surface to volume 
$\left(S_{s p} / V_{s p}\right)$ of spacer filament, one can estimate the gap between spacer-filled channels from equation (8) ${ }^{24-25}$.

$$
d_{h}=\frac{4 \varepsilon}{\frac{2}{h}+(1-\varepsilon) \cdot S_{s p} / V_{s p}}
$$

Both compartments were made from the same spacer filament, therefore, equally thick, and both compartments used the same feed solution; pumping loss can be given by equation (9) 26

$$
P_{\text {loss }}=\frac{\Delta P \cdot Q}{A}=\frac{12 \mu \cdot L^{2} \cdot h \cdot \varepsilon}{t_{r e s}^{2} \cdot \frac{1}{4} \cdot d_{h}^{2}}
$$

Where $A$ is the active membrane area in $\mathrm{m}^{2}$ and $\mathrm{Q}$ feed solution flow rate in $\mathrm{m}^{3} \mathrm{~s}^{-1}$. Theoretically, RED stack resistance is given by equation 10 .

$$
R_{\text {stack }}=\frac{N}{A_{\text {mem }}}\left(R_{A}+R_{C}+\frac{d_{c}}{k_{c}}+\frac{d_{d}}{k_{d}}\right)+R_{e}
$$

$\mathrm{N}$ is the number of cell pairs (alternate arrangement of anion- and cation-exchange membranes), A is the effective area of both the membranes $\left(\mathrm{m}^{2}\right), \mathrm{R}_{\mathrm{A}}$ is the anion exchange membrane resistance $\left(\Omega \mathrm{m}^{2}\right), R_{c}$ is the cation exchange membrane resistance $\left(\Omega \mathrm{m}^{2}\right), \mathrm{d}_{\mathrm{c}}$ is the thickness of the compartment with the concentrated solution $(\mathrm{m}), \mathrm{k}_{\mathrm{c}}$ is its ionic conductivity $\left(\mathrm{S} \mathrm{m}^{-1}\right)$, $\mathrm{d}_{\mathrm{d}}$ is the thickness of the compartment with the diluted solution $(\mathrm{m})$, $\mathrm{k}_{\mathrm{d}}$ is its ionic conductivity $\left(\mathrm{S} \mathrm{m}^{-1}\right)$, and $\mathrm{Re}$ is the electrode resistance $(\Omega)$. Reducing the stack resistance is an essential factor for enhancing the net output power, but other factors also influence the cell performance ${ }^{27}$, which also need to be considered. The spacer shadow effect, feed solution flow, compartment width, and feed solution concentration are also important.

The ohmic resistance of the ion-exchange membrane and the solution is given by equation (11).

$$
R_{\text {Ohmic }}(z)=\frac{1}{\beta}\left(R_{A}+R_{C}+\frac{\delta_{H}}{\Lambda_{H}(Z) \mathrm{C}_{H}(z)}+\frac{\delta_{L}}{\Lambda_{L}(Z) \mathrm{C}_{L}(z)}\right)
$$

Here, $\mathrm{R}$ is the membrane resistance, $\beta$ is the open ratio of the spacer used in the sack, $\delta_{H}$ and $\delta_{L}$ are the width of the compartment with a high and low concentration of the solution, $\Lambda_{H}$ and $\Lambda_{L}$ are the molar conductivity of the high concentration and low concentration solution.

The non-ohmic resistance of the stack is given by equation (12)

It is calculated by estimating the concentration of polarization (CP) at the ion-exchange membrane, which is evaluated by placing the value of channel length, the flow rate of solution, and flow structure. 


$$
R_{C P}=0.31 t_{H} \frac{\delta_{H}}{L}+0.31 t_{L} \frac{\delta_{L}}{L}+0.05
$$

Where, $t_{H}$ and $t_{L}$ are residence times of high-concentration and low-concentration solution, and $L$ is the length of the channel.

Theoretical calculation of OCV given by Nernst equation (13):

$$
V_{O C}=\left(\alpha_{C E M}+\alpha_{A E M}\right) \frac{R_{g} T}{z F} \ln \frac{\gamma_{s} c_{s}}{\gamma_{r} c_{r}}
$$

$\alpha$ is the transference number of an ion-exchange membrane (IEM), $R_{g}$ is the universal gas constant $\left(8.134 \mathrm{~J} \mathrm{~mol}^{-1} \mathrm{~K}\right), \mathrm{T}$ is the temperature in $\mathrm{K}, \mathrm{z}$ is the valency number of ion, $\mathrm{F}$ is the Faraday constant $\left(96485 \mathrm{C} \mathrm{mol}^{-1}\right), \gamma$ is the activity coefficient, $\mathrm{c}$ is the concentration of ions, and $\mathrm{s}$ and $\mathrm{r}$ as subscript represent the HC and LC solutions.

For evaluating perm-selectivity of IEM, the Nernst equation used

$$
V_{O C}=\left(\alpha_{C E M}+\alpha_{A E M}\right) \frac{R_{g} T}{z F} \ln \frac{\gamma_{H}(z) c_{H}(z)}{\gamma_{L}(z) c_{L}(z)}
$$

Here, $\mathrm{H}$ and $\mathrm{L}$ subscript represents the high concentration and low concentration of the solution.

The current is estimated from equation (15)

$$
I(z)=\frac{V_{O C}(z)}{R_{\text {internal }}(z)+R_{\text {external }}}
$$

Where, $R_{\text {internal }}$ is the internal resistance, which is the sum of Ohmic resistance and concentration of polarization resistance, and $R_{\text {external }}$ is stack's external resistance. However, the current density is evaluated by integrating the previous equation (15), which is given by equation (16).

$$
j=\frac{\sum_{z=0}^{L} I(z) d z}{2 L W}
$$

Therefore, the power output from the stack is derived from equation (17)

$$
P(z)=I(z)^{2} R_{\text {external }}
$$

Power density is given by equation (18)

$$
P_{d}=\frac{\sum_{z=0}^{L} P(z) d z}{2 L W}
$$


(A)

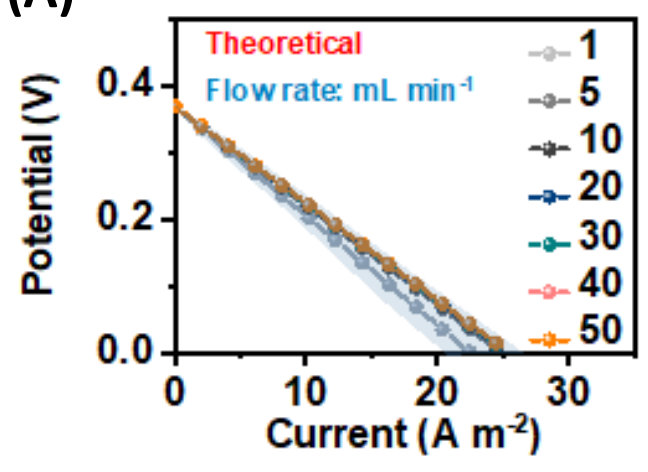

(C)

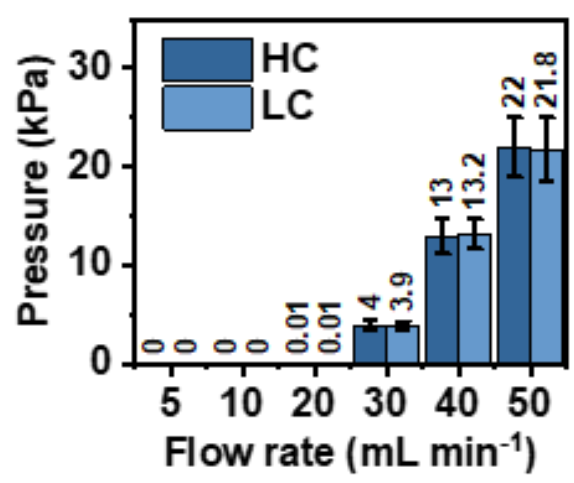

(B)

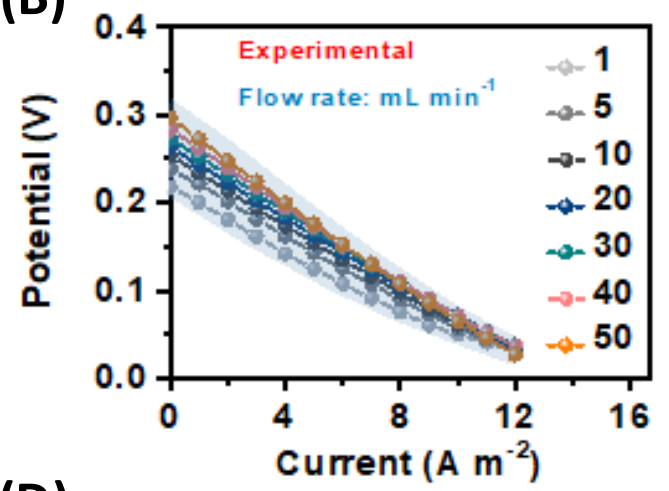

(D)

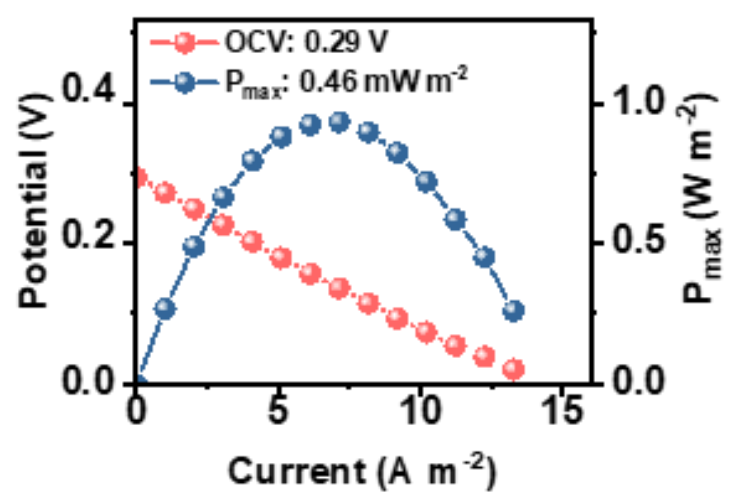

Figure S17 Reverse electrodialysis output performance using COF based matrix interconnected membrane: (A) Theoretically obtain open-circuit voltage with varying flow rate, (B) Experimentally obtain open-circuit voltage with varying flow rate, (C) Hydrodynamic pressure loss in $\mathrm{kPa}$, and (D) optimized maximum power density and potential at flow rate $40 \mathrm{~mL} \mathrm{~min}^{-1}$. 

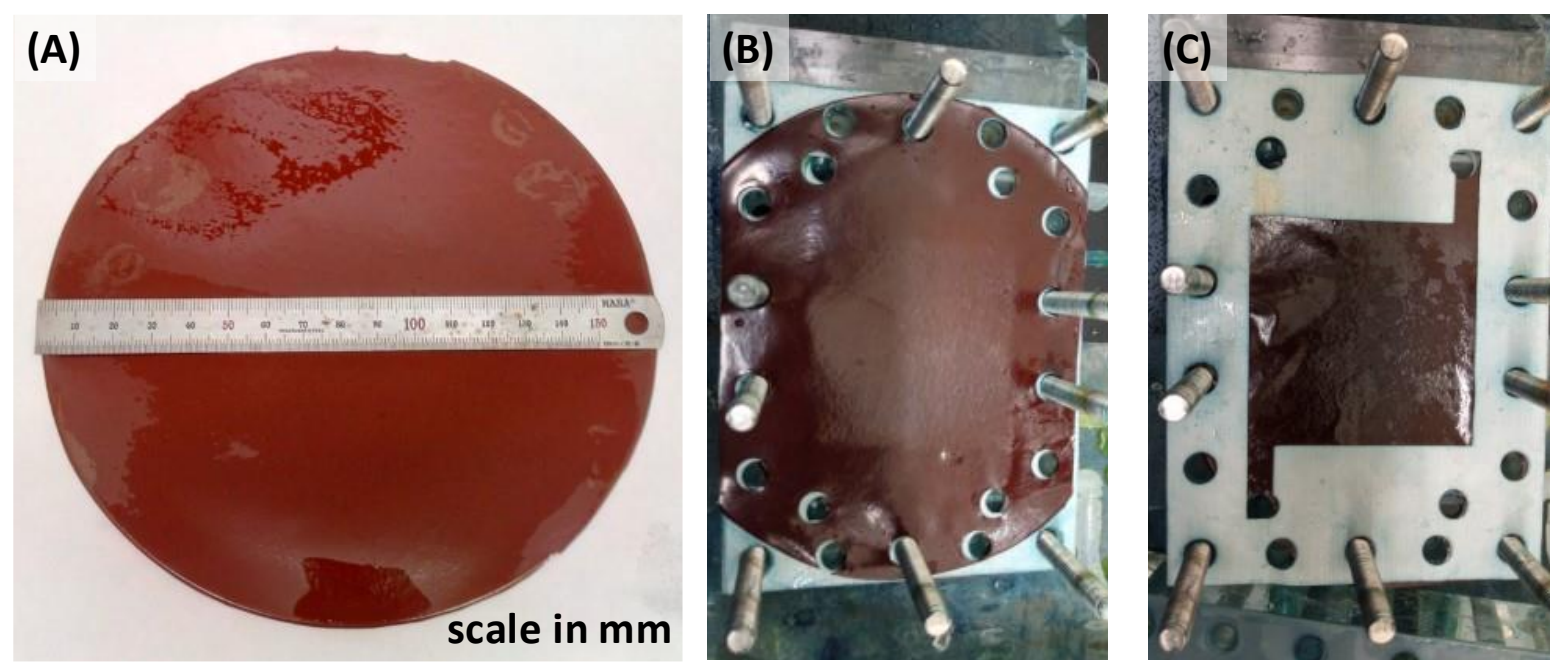

Figure S18 Photograph of the large-area membrane and stack: (A) large-area COFbased matrix interconnected membrane with diameter $\sim 16 \mathrm{~cm}$, (B) RED stack without gasket, and (C) RED stack with gasket effective area $49 \mathrm{~cm}^{2}$. 


\section{Note S3 Internal resistance of the stack}

Potential across working electrodes of RED stack measured by galvanostat method, at the fixed current step of $5 \mathrm{~mA}$ applied for $60 \mathrm{~s}$. During this period, ions diffuse towards the working electrode to stabilize the applied current. The obtained potential versus time

plot shows, as the flow rate increases, the internal resistance of the stack also increases from 3.2 to $5.4 \Omega$ (see figure $\mathrm{S} 19 \mathrm{~A}$ ). 


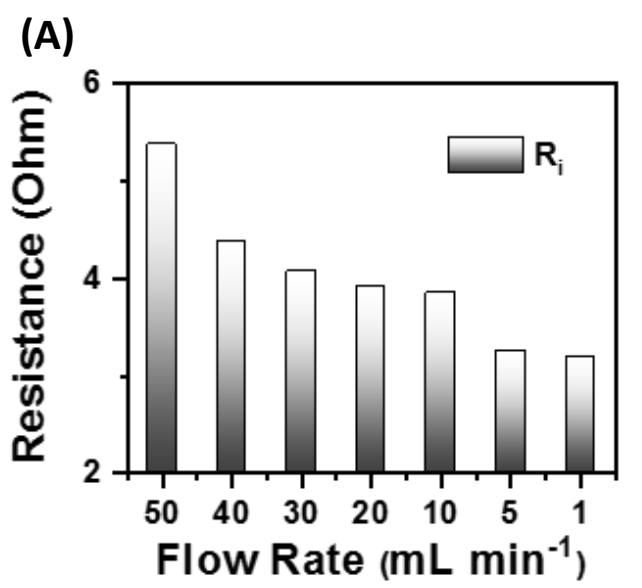

(B)

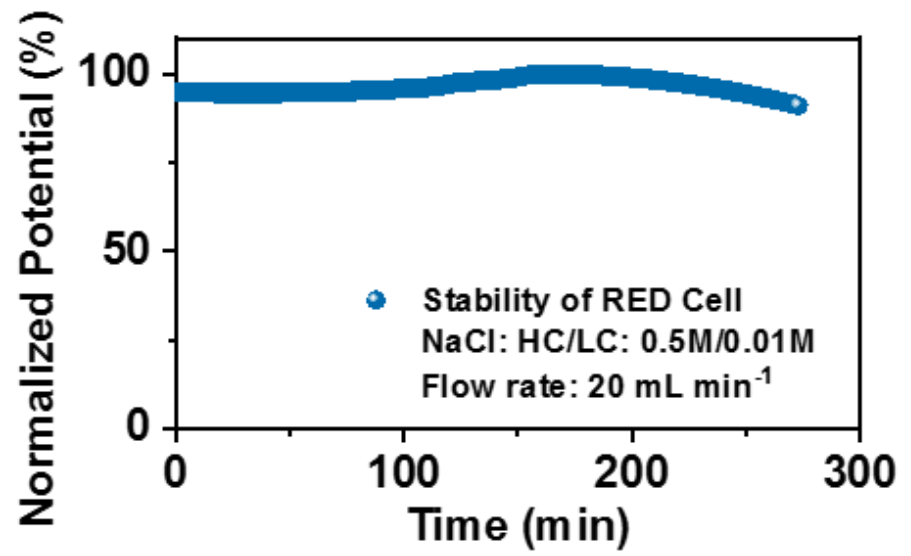

Figure S19 (A) Internal resistance of the stack with varying flow rate from 50 to $1 \mathrm{~mL}$ min $^{-1}$, and (B) Long-run stability of the RED stack at ambient condition. 


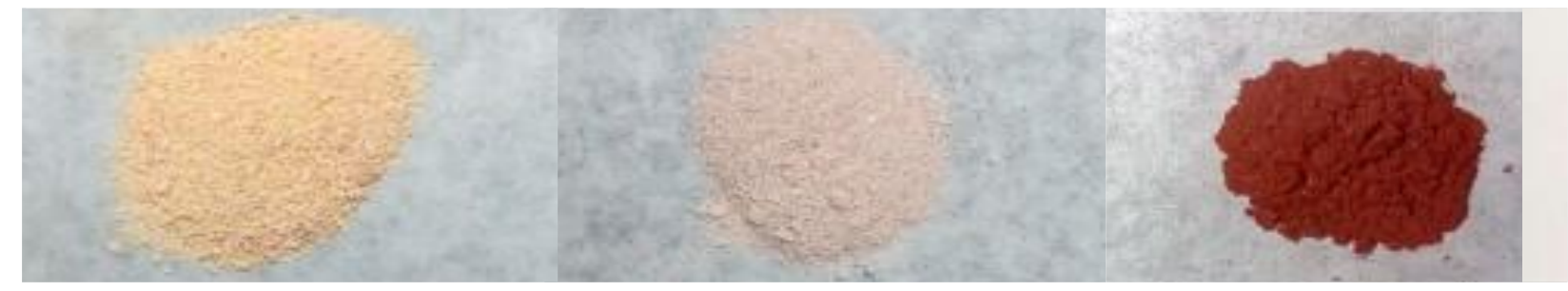

Figure S20 Digital photograph of synthesized Materials: 1,3,5-tri formyl phloroglucinol linker, p-phenylenediamine, and covalent-organic framework powder. 
${ }^{13}$ C-NMR

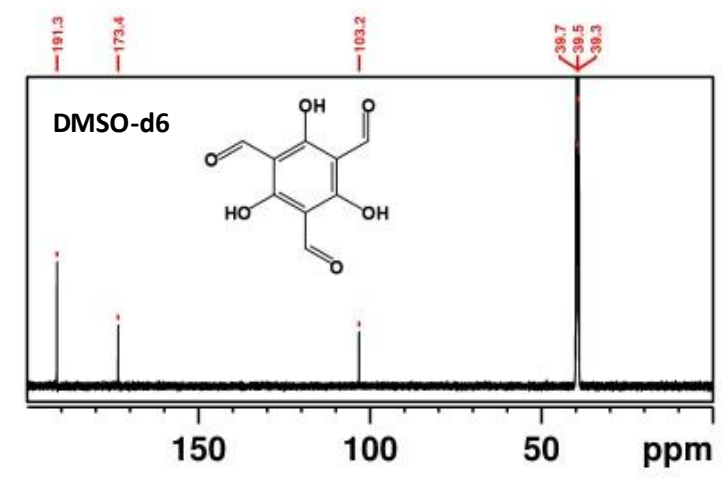

${ }^{1} \mathrm{H}-\mathrm{NMR}$

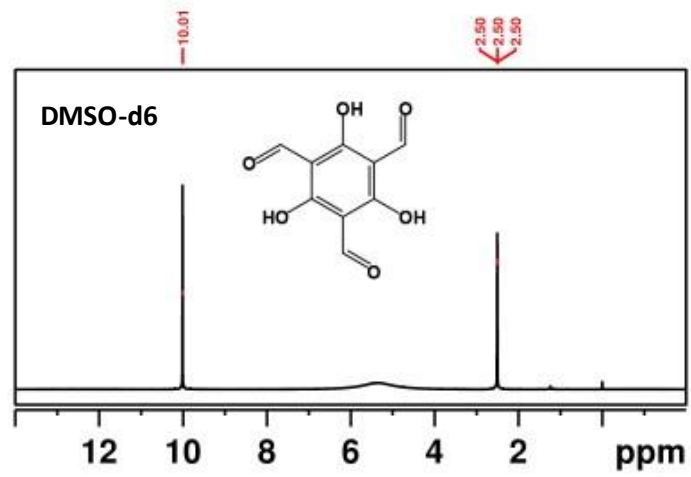

Figure S21 Nuclear magnetic resonance (NMR) spectra (500 MHz, DMSO-d6): (A) ${ }^{13} \mathrm{C}$ NMR spectra shows peak position of the aldehyde carbonyl group $(\mathrm{C}=0)$ at $\delta=191.3 \mathrm{ppm}$ for 1,3,5-triformylphloroglucinol linker and (B) Singlet with $8 \mathrm{H}$ in ${ }^{1} \mathrm{H}$ NMR spectra of 1,3,5-triformylphloroglucinol linker. 


\section{(A)}

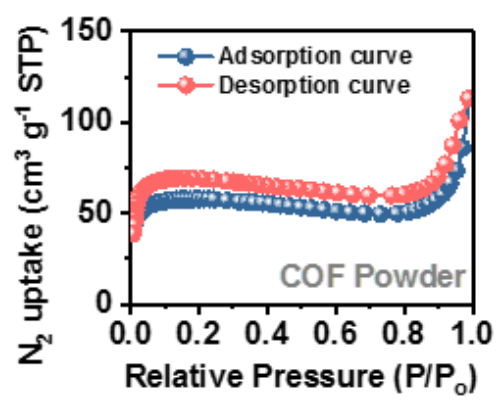

(B)

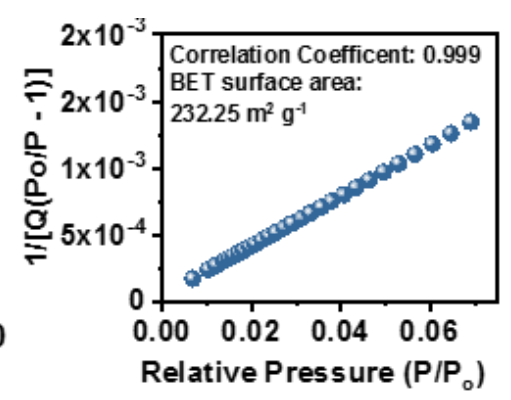

(C)

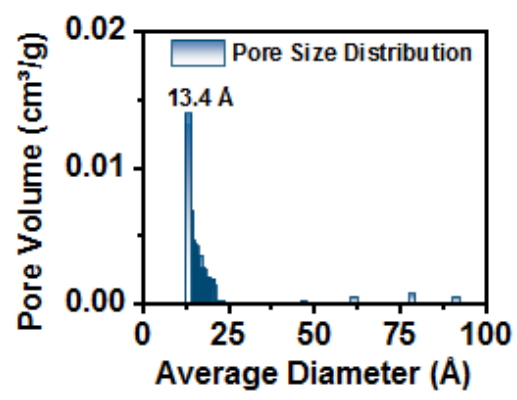

Figure S22 Surface area and Pore size distribution of the prepared covalent organic

framework: (A) $\mathrm{N}_{2}$ adsorption-desorption isotherms graphs show the quantity absorbed in $\mathrm{cm}^{3} \mathrm{~g}^{-1}$ with varying relative pressure (B) BET surface area plot evaluated from isotherm, and (C) BJH adsorption pore size distribution. 


\section{Nomenclature}

$\mathrm{RH}$

$P_{\max }$

$U_{\text {stack }}$

Istack

Amem

$P_{\text {net }}$

Ploss

$Q_{H}$

$Q_{L}$

$\Delta P_{H}$

$\Delta P_{L}$

$\eta_{\text {pump }}$

$\Delta P$

$\mu$

$L$

tres

$d_{h}$

$b$

$h$

$\varepsilon$

$S_{s p} / V_{s p}$

$N$

$R_{A}$

$R_{C}$

$d_{c}$

$k_{c}$

$d_{d}$

$k_{d}$

$R_{e}$

IEC

$\sigma$

Wdry

$W U$

$W_{\text {wet }}$

$T_{g}$
Relative humidity, \%

Maximum power density, $\mathrm{W} \mathrm{m}^{-2}$

Potential, $\mathrm{V}$

Current, A

Effective membrane area, $\mathrm{m}^{2}$

Actual total power density, $\mathrm{W} \mathrm{m}^{-2}$

Hydrodynamic power loss (pumping loss), $\mathrm{W} \mathrm{m}^{-2}$

The flow rate in the high concentration compartment, $\mathrm{mL} \mathrm{mim}^{-1}$

The flow rate in the low concentration compartment, $\mathrm{mL} \mathrm{mim}^{-1}$

Pressure drop in high concentration compartment, $\mathrm{Pa}$

Pressure drop in low concentration compartment, $\mathrm{Pa}$

Pumping efficiency, \%

Pressure difference over feed water compartment, $\mathrm{Pa}$

Viscosity of water, Pa.s

Length of membrane, $\mathrm{cm}$

Residence time, $\mathrm{s}$

Hydraulic diameter of the channel, $m$

Width of each channel between membrane, $m$

Intermembrane distance, $\mathrm{m}$

Porosity

The ratio of surface to volume of spacer filament

Number of cell pairs (anion and cation exchange membrane)

Anion exchange membrane resistance, $\Omega \mathrm{m}^{2}$

Cation exchange membrane resistance, $\Omega \mathrm{m}^{2}$,

Thickness of the compartment with concentrated solution, $\mathrm{m}$

Ionic conductivity of the concentrated solution, $\mathrm{S} \mathrm{m}^{-1}$

Thickness of the compartment with diluted solution, $\mathrm{m}$

Ionic conductivity of the diluted solution, $\mathrm{S} \mathrm{m}^{-1}$

Electrode resistance, $\Omega$

Ion exchange capacity, meq $\mathrm{g}^{-1}$

Ionic conductivity, $\mathrm{S} \mathrm{cm}^{-1}$

Weight of the dry membrane, $g$

Water uptake, \%

Weight of the hydrated membrane, $g$

Glass transition temperature, ${ }^{\circ} \mathrm{C}$ 


\section{Supporting References:}

1. Rubatat, L.; Rollet, A. L.; Gebel, G.; Diat, O., Evidence of elongated polymeric aggregates in Nafion. Macromolecules 2002, 35 (10), 4050-4055.

2. Luu, D. X.; Cho, E.-B.; Han, O. H.; Kim, D., SAXS and NMR analysis for the cast solvent effect on sPEEK membrane properties. The Journal of Physical Chemistry B 2009, 113 (30), 10072-10076.

3. Gebel, G., Structure of Membranes for Fuel Cells: SANS and SAXS Analyses of Sulfonated PEEK Membranes and Solutions. Macromolecules 2013, 46 (15), 6057-6066.

4. Hickner, M. A.; Ghassemi, H.; Kim, Y. S.; Einsla, B. R.; McGrath, J. E., Alternative polymer systems for proton exchange membranes (PEMs). Chem Rev 2004, 104 (10), 4587-4611.

5. Putnam, C. D., Guinier peak analysis for visual and automated inspection of small-angle X-ray scattering data. J Appl Crystallogr 2016, 49 (Pt 5), 1412-1419.

6. Yang, Z.; Chen, P.; Hao, W.; Xie, Z.; Feng, Y.; Xing, G.; Chen, L., Sulfonated 2D Covalent Organic Frameworks for Efficient Proton Conduction. Chemistry - A European Journal 2021, 27 (11), 38173822.

7. Peng, Y.; Xu, G.; Hu, Z.; Cheng, Y.; Chi, C.; Yuan, D.; Cheng, H.; Zhao, D., Mechanoassisted Synthesis of Sulfonated Covalent Organic Frameworks with High Intrinsic Proton Conductivity. Acs Appl Mater Inter 2016, 8 (28), 18505-18512.

8. Chandra, S.; Kundu, T.; Dey, K.; Addicoat, M.; Heine, T.; Banerjee, R., Interplaying Intrinsic and Extrinsic Proton Conductivities in Covalent Organic Frameworks. Chemistry of Materials 2016, 28 (5), 1489-1494.

9. Chandra, S.; Kundu, T.; Kandambeth, S.; BabaRao, R.; Marathe, Y.; Kunjir, S. M.; Banerjee, R., Phosphoric Acid Loaded Azo (-N=N-) Based Covalent Organic Framework for Proton Conduction. Journal of the American Chemical Society 2014, 136 (18), 6570-6573.

10. Shinde, D. B.; Aiyappa, H. B.; Bhadra, M.; Biswal, B. P.; Wadge, P.; Kandambeth, S.; Garai, B.; Kundu, T.; Kurungot, S.; Banerjee, R., A mechanochemically synthesized covalent organic framework as a proton-conducting solid electrolyte. Journal of Materials Chemistry A 2016, 4 (7), 2682-2690.

11. Sasmal, H. S.; Aiyappa, H. B.; Bhange, S. N.; Karak, S.; Halder, A.; Kurungot, S.; Banerjee, R., Superprotonic Conductivity in Flexible Porous Covalent Organic Framework Membranes. Angewandte Chemie International Edition 2018, 57 (34), 10894-10898.

12. $\mathrm{Xu}, \mathrm{H} . ;$ Tao, S.; Jiang, D., Proton conduction in crystalline and porous covalent organic frameworks. Nature Materials 2016, 15 (7), 722-726.

13. Ma, H.; Liu, B.; Li, B.; Zhang, L.; Li, Y.-G.; Tan, H.-Q.; Zang, H.-Y.; Zhu, G., Cationic Covalent Organic Frameworks: A Simple Platform of Anionic Exchange for Porosity Tuning and Proton Conduction. Journal of the American Chemical Society 2016, 138 (18), 5897-5903.

14. Ranjeesh, K. C.; Illathvalappil, R.; Veer, S. D.; Peter, J.; Wakchaure, V. C.; Goudappagouda; Raj, K. V.; Kurungot, S.; Babu, S. S., Imidazole-Linked Crystalline Two-Dimensional Polymer with Ultrahigh Proton-Conductivity. Journal of the American Chemical Society 2019, 141 (38), 14950-14954.

15. Meng, Z.; Aykanat, A.; Mirica, K. A., Proton Conduction in 2D Aza-Fused Covalent Organic Frameworks. Chemistry of Materials 2019, 31 (3), 819-825.

16. Montoro, C.; Rodríguez-San-Miguel, D.; Polo, E.; Escudero-Cid, R.; Ruiz-González, M. L.; Navarro, J. A. R.; Ocón, P.; Zamora, F., Ionic Conductivity and Potential Application for Fuel Cell of a Modified Imine-Based Covalent Organic Framework. Journal of the American Chemical Society 2017, 139 (29), 10079-10086.

17. Yang, Y.; He, X.; Zhang, P.; Andaloussi, Y. H.; Zhang, H.; Jiang, Z.; Chen, Y.; Ma, S.; Cheng, P.; Zhang, Z., Combined Intrinsic and Extrinsic Proton Conduction in Robust Covalent Organic Frameworks for Hydrogen Fuel Cell Applications. Angewandte Chemie International Edition 2020, 59 (9), 36783684. 
18. Hatzell, M. C.; Ivanov, I.; Cusick, R. D.; Zhu, X.; Logan, B. E., Comparison of hydrogen production and electrical power generation for energy capture in closed-loop ammonium bicarbonate reverse electrodialysis systems. Phys Chem Chem Phys 2014, 16 (4), 1632-1638.

19. Zhu, X. P.; He, W. H.; Logan, B. E., Reducing pumping energy by using different flow rates of high and low concentration solutions in reverse electrodialysis cells. J. Membr. Sci. 2015, 486, 215221.

20. Veerman, J.; Saakes, M.; Metz, S. J.; Harmsen, G. J., Reverse electrodialysis: Performance of a stack with 50 cells on the mixing of sea and river water. J. Membr. Sci. 2009, 327 (1-2), 136-144.

21. Veerman, J.; Saakes, M.; Metz, S. J.; Harmsen, G. J., Electrical power from sea and river water by reverse electrodialysis: a first step from the laboratory to a real power plant. Environ Sci Technol 2010, 44 (23), 9207-9212.

22. Batchelor, C. K.; Batchelor, G. K., An Introduction to Fluid Dynamics. Cambridge University Press: Cambridge, U.K., 2000.

23. Schock, G.; Miquel, A., Mass transfer and pressure loss in spiral wound modules. Desalination 1987, 64, 339-352.

24. Da Costa, A. R.; Fane, A. G.; Wiley, D. E., Spacer characterization and pressure drop modelling in spacer-filled channels for ultrafiltration. J. Membr. Sci. 1994, 87 (1-2), 79-98.

25. Vermaas, D. A.; Veerman, J.; Saakes, M.; Nijmeijer, K., Influence of multivalent ions on renewable energy generation in reverse electrodialysis. Energy Environ. Sci. 2014, 7 (4), 1434-1445.

26. Vermaas, D. A.; Saakes, M.; Nijmeijer, K., Enhanced mixing in the diffusive boundary layer for energy generation in reverse electrodialysis. J. Membr. Sci. 2014, 453, 312-319.

27. Geise, G. M.; Curtis, A. J.; Hatzell, M. C.; Hickner, M. A.; Logan, B. E., Salt concentration differences alter membrane resistance in reverse electrodialysis stacks. Environmental Science \& Technology Letters 2014, 1 (1), 36-39. 